\title{
The Struggles of Co-creation - The Highs and Lows of Involving Stakeholders into the Service Design Process
}

\author{
Fredrik Sandberg ${ }^{1}$, Bo Westerlund ${ }^{2}$, Erik Widmark $^{3}$, and Sophie Andersson ${ }^{3}$, \\ ${ }^{1}$ Linnaeus University, School of Design, \\ SE-39182 Kalmar, Sweden \\ Fredrik.sandberg@lnu.se \\ ${ }^{2}$ Konstfack, LM Ericssons väg 14, \\ Box 3601 Stockholm, Sweden \\ bo. westerlund@konstfack. se \\ ${ }^{3}$ Transformator Design AB, Götgatan 19, \\ 11646 Stockholm, Sweden \\ \{erik.widmark, sophie.andersson\} @transformatordesign.se
}

\begin{abstract}
This paper presents our experiences from a research project on how to co-develop new methods for idea generation within a service design practice. As an example the paper describes how service designers used two visual inquiry methods together with customers and employees in different service situations. The results show that that there is great potential in developing methods for co-design work based on design approaches. This project relies on a mindset where materials of different kinds, that can be organized and reorganized in different ways are used. This supports a way of creating knowledge that facilitates production of other results than the purely verbal. We have also realized that it requires a great amount of work to achieve a great result.
\end{abstract}

Keywords: Business Development, Co-creation, Co-Design, Idea Generation, Visual Methods, Service Design.

\section{Introduction}

In this paper we present our experiences from a shorter pilot study on how service designers can use visual inquiry methods to engage with and create knowledge about people's service experiences, needs and expectations.

The main objective with the study was to explore and develop two methods for idea generation in the beginning of a service design process. The aim was that these methods would be based on co-design, i.e. to let customers, employees and other stakeholders create knowledge together, which many consider to be a very successful approach to create innovative solutions [10], [12]. Researchers from various fields have for many years claimed that the design praxis is undergoing a radical transformation and therefore needs new relevant design methods [10], [3]. Some of the newer methods that are used in design and service design processes have their 
roots in ethnology and are considered to support the understanding of user needs and their preferences. Other methods have a background in marketing or business development. Often methods with very different ethos are mixed without awareness of the methods' different intrinsic approach. Design work creates awareness of future opportunities. In this knowledge based work, it is an advantage if people with many different skills and experience are involved. Co-creation and co-design is considered by many to be very successful approaches in order to create innovative proposals. Others believe however, that it is too costly and time consuming to involve many different stakeholders in the design work. The focus of this project was therefore to experiment with and analyze the processes of co-design and co-creation and try to create a methodology and comprehensive approach to this work be performed in an economically satisfactory manner.

Within this research project focus has been on methods that are design-related, i.e. methods that support work with a design point of ethos. The learning is largely taking place by simultaneously working with the proposed solution and the severity of the situation, which is often referred to as a "wicked problem" [7]. Assessments are the only way to evaluate, because within this design approach there's no right or wrong way, only better and less good suggestions seen from a specific perspective [1]. The work of this research project is characterized by the exploratory approach using visual and physical tools. The knowledge created often contained more useful nuances than words alone.

The design approach can be perceived as imprecise and uncertain by people from other backgrounds used to solve distinct and well-defined problems. It is therefore important to be able to demonstrate the results of these methods and their ability to create knowledge and ideas for desirable, profitable, future products and services. We begin by describing the project background, and then describe the two visual methods and our experiences using them in a research project. We conclude by suggesting how others can use the method and describing how we hope to use it in the future.

\section{$2 \quad$ Project Background}

The study was a collaboration project between a group of design researchers from two universities; Linneaus University (Lnu), and Konstfack (KF) and a group of design practitioners from Transformator Design AB (TD). The study of the methods took place during a five month period inside a real design case called $\mathrm{ABC}$ that $\mathrm{TD}$ was responsible for. The aim of $\mathrm{ABC}$ was to help a service provider (the client) to create significantly better service experiences for its customers. In order to create knowledge about how both TD and the other stakeholders experienced the two inquiry methods, we visited different service situations where we tested, analyzed and interviewed both service providers and service buyers.

\subsection{Aim and Research Questions}

- How will service designers perceive visual inquiry methods?

- What usability and experience issues will be found from the method prototypes? 


\subsection{Method}

This study consists of the design and evaluation of two visual inquiry methods.

\section{Prototype Development}

In order to test and evaluate the two inquiry methods, a series of different paper prototypes was designed and used in live settings.

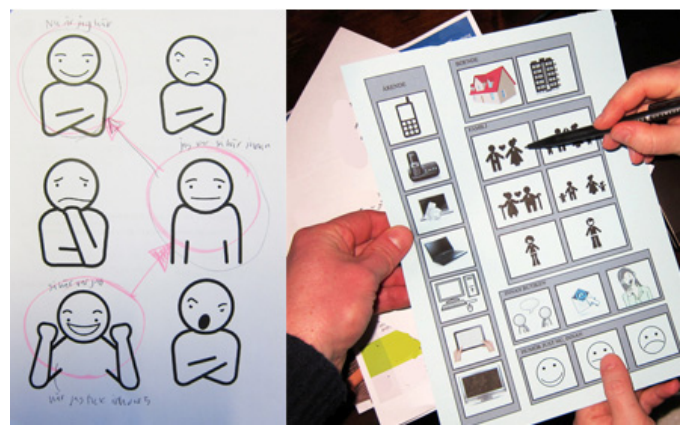

Fig. 1. Discussions among the project participants about the first versions of prototypes 1 and 2 . By ensuring that all participants could see and touch the prototypes, the group could empathize with how the methods might be experienced in different contexts.

\subsection{Prototyping Method 1}

The inspiration for the prototypes of method 1 comes directly from Lucy Kimbell [2]. It is a method founded on an icon-based interface. The method supports both designers and non-designers to start building a better understanding of how people/customers are a part of a large network and the fact that they are not independent actors. Every human being is always and all the time linked with a number of people, organizations and objects.

These people, organizations and objects can act as generators to create new ideas. By bringing together or replace any of the above things, new ideas and design opportunities will emerge. This phenomenon is called bisociation in the field called collective creativity [10].

Story world can be used as an aid in both individual interviews and in collaborative design activities. In interview situations, the method is meant to be used as a support and basis for the questions by the interviewer to the interviewee.

By using the different icons in the method you will create a collaborative picture of how things fit together. Both the one who asks the questions and the one who answers are given the opportunity to generate new ideas.

"With this method services can become more valuable to customers and users, Easier-to-use, with fewer resources wasted on implementing the right ideas in the wrong way (or on the wrong ideas entirely)"

(Kimbell \& Julier 2012). 


\subsection{Prototyping Method 2}

The inspiration for the prototypes of method 2 comes from a tool that was already part of TD's work process. It was a LEAN inspired whiteboard where employees of TD could use colored post-it notes to show the executed and non-executed tasks [4]. The aim of method 2 was to use a version of TD's Lean-inspired whiteboard as part of communicate and move idea generation to where the employees context.

The boards described a number of tasks, both using images and text that the customer service employees in the $\mathrm{ABC}$ project should test in their meetings with the customers. When the customer service staff in the $\mathrm{ABC}$ project performed tasks they wrote down what they did and how they felt on post it notes and then placed them on the board where they thought they belonged. The idea of the boards was that they should work both with and without support from TD. Once a week TD would visit the workplaces to collect the thoughts and ideas that the employees had created. These ideas were then refined by TD and reused in a variety of collaborative design activities with participants in the $\mathrm{ABC}$ project.

\section{$4 \quad$ Testing the Method Prototypes}

The first method tested in the study was method 1. It was tested in stores by three designers from TD. The test opportunity was a half-day activity where TD could try out the method on six different customers. The method is also used for a longer interview. Because of the tight schedule of the $\mathrm{ABC}$ project, there was no time for any follow-ups to further test the method in stores. The material created during the tests were picked out and reused in another activity the next day.
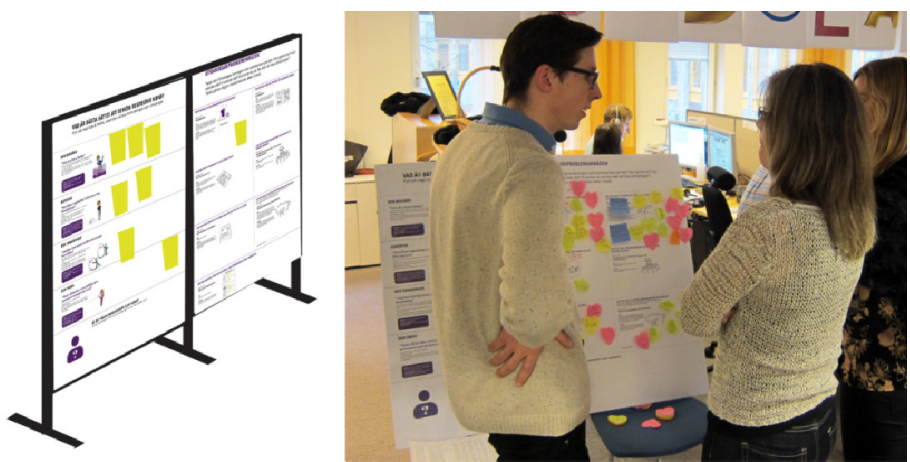

Fig. 2. The second generation of method 2 was tested on employees in the customer support. Method 2 became a meeting point for TD and the ABC Company. The boards created a curiosity among the staff and this led to new dialogues between the different departments.

During the tests of method 2 the boards were placed in both stores and in the customer support office. In the shops the boards were cramped in to already minimal coffee and lunch rooms therefore they were hard for the employees to use. But in the office of customer support the boards could take a more central role. It was placed on the middle of the customer service staff workroom, where it was visible from all sides. 


\section{$5 \quad$ Evaluating the Prototypes}

The methods and results were mainly evaluated continuous throughout the project, both by TD and the researchers. But at three specific occasions the team earmarked time to reflect and evaluate the results.

The first occasion was a collaborative mapping activity that the researchers had created and led. In this activity, all project participants created a large map of the things they had done and experienced so far during the project. By using this way to create knowledge, the researchers could visually follow the participants' perception of where the problems, ideas, conflicts, comments, mistakes and creativity had occurred during the project. This way of evaluating the methods gave us a good picture of the context and network that the methods, project and the people belonged.

The second evaluation time was an anonymous questionnaire that was sent out to all project participants from TD. The idea of the survey was to focus the questions and answers only to method 1 and 2. Because of the tight schedule of the ABC project this survey was not prioritized by TD. Only one survey came back to the researchers.

The third and last assessment was an attempt to move both the participants and the methods out of the ABC project and into a lab environment at Konstfack. The purpose of this was to get away from the frames of the $\mathrm{ABC}$ project put on the research project. We wanted to see if we could lift the methods from a specific context and evaluate and develop them from a more general perspective. Three of the participants from TD and researchers attended the meeting. The activity lasted for about two hours and during that time managed the group discuss the methods and developed the icon tool into four new concepts on how the tool could work in a digital environment, like the iPad.

\section{$6 \quad$ Results}

Based on the three evaluation assessments, we can only highlight a few, incomplete and general conclusions about the methods. But after listening and reading TD's opinions on method 1 , we can generally say that the method was appreciated in particular the icons with different facial expressions. The icons change TD's normal work process where visualization and idea generation usually comes more towards the end of the design process. But because of facial icons TD started to create and use ideas and visual solutions at the beginning of the ABC project. Another noticeable change was that the face icons gave TD a more nuanced picture of the client's situation than what TD usually gets when they use other methods. Through facial icons customers were forced to really think about which emotion best matched their experiences.

Method 2 was perceived by TD as stiff and sometimes hard to use. When TD was not in place, the methods were not used. In the stores, they were not used at all. But as soon as TD was in place and was able to coach the employees, the boards worked much better. The boards became a place where both TD and the employees could interact. The boards could be seen as boundary objects [11]. 
What was perceived as bad with the method 2 was that it did not encourage a dialogue between TD and the employees. It was also difficult to understand the pieces of information that the employees posted on the board. Although there were many new and exciting ideas it was in the end difficult to trace them to the person and context. The methods were overall appreciated by TD but they will need more time and experience to refine them. The fragments that we managed to gather during the research project suggest however that the methods succeeded in generating relevant ideas and involve more stakeholders in the TD-design process.

\section{$7 \quad$ Reflections}

The conditions for implementing this project have been very good. Service designers with highly relevant knowledge and experience have been working closely together with scientists who have extensive experience in the development of design methods. The ABC project, where the exploratory work has been conducted has offered a great complexity and many diverse environments and situations to work with method development.

\subsection{Conflicting Goals}

The designer often empathizes with the end-user (customer's customer) but often the client has the most say in the project. It may seem like conflict to choose whether to focus on what is valuable to the "end user" or the company's sales and profits. The concept of value is itself an example of the different discourses used. A common discourse argue that value is created in the moment of use, ie. when the end user uses a product or service that creates value for this person [3]. This can be seen as a relational and constructivist approach, which believes that individuals perceive certain events as meaningful and that give people value. Products and services have meaning and value is created when used [3]. This approach is advocated widely including one of the most important business thinkers of our time, CK Prahalad. He wrote that "value is based on unique, personalized experiences of consumers." And "even companies serving 100 million consumers need to focus on Individuals." [6]. In design, with its focus on the "end user", it is obvious that the value is created during use. Both these approaches have their own logic, but if these two very different approaches to the concepts of value occurs in the same project, it is easily creates confusion and uncertainty. In the past decade we have increased our understanding of the above dilemma when forced to choose the focus on either the user or the others involved, such as the employees. In order to work against several unclear interlinked objectives, we believe that a tangible exploration approach may have more success than one that relies on only verbal arguments. But the language is of course extremely important, and it is of the utmost importance that the work gives heed to the concepts of different and constantly changing interpretations and reinterpretations. 


\subsection{Co-design, Does It Mean Extra Work?}

The work with co-design in this research project has taken much more time than estimated. It seems that the work has given very good results in terms of knowledge of customers and employees, and also concrete concepts for improving the customer service of $\mathrm{ABC}$. This preliminary study has shown that there is great potential in developing methods for co-design work based on design mentality. I.e. that projects uses a mindset where materials of different kinds can be organized in different ways, thus supporting a different way of creating knowledge than the purely verbal.

We have also realized that it requires a great amount of work to achieve a great result.

Transformator Design had already good experiences of having the customers' involved in the design process, but they partly lacked a clear methodology and comprehensive approach on how this work can be done in an efficient manner. This project has demonstrated that a co-design work can give very good result, but it takes a lot of work. In conclusion, we believe that it is possible to further develop and refine these methods so that they become more efficient.

\section{Conclusions and Further Research}

This paper has presented a project that should be seen more as a pre-study and the results indicate interesting possibilities for future explorations. Co-design was the overall approach and the way of involvement was through a visual thinking approach where materials were used that afforded to be organized and reorganized in different ways. This enabled stakeholders to contribute with relevant input and reflections to the larger commercial project that this study was part of. The emphasis of the final workshop was to develop opportunities for further research and here it was obvious that some kind of development of software support for service design processes is desirable. The challenge here will be to support the ease of manipulation, structuring and restructuring of the information that seems to be key affordances of the methods being developed, while at the same time integrate the possibilities that software has over physical artifacts.

\section{References}

1. Cross, N.: Designerly ways of knowing. Design Studies 3(4), 221-227 (1982)

2. Kimbell, L., Julier, J.: The Social Design Methods Menu (2012), http: / /www. lucykimbell.com/stuff/Fieldstudio_SocialDesignMet hodsMenu.pdf (retrieved February 27, 2013)

3. Krippendorff, K.: The Semantic Turn: A New Foundation for Design. Taylor \& Francis, Boca Raton (2006)

4. Liker, J.K.: The Toyota Way - Lean for excellence. Liber, Malmö (2009)

5. Nelson, H.G., Stolterman, E.: The design way: intentional change in an unpredictable world. MIT Press, Cambridge (2012)

6. Prahalad, C.K., Krishnan, M.S.: The New Age of Innovation: Driving Co-created value through global networks. McGraw-Hill Professional, New York (2008) 
7. Rittel, H., Webber, M.: Dilemmas in a General Theory of Planning. Public Sciences 4, 155-169 (1973)

8. Sandberg, F.: Visual Inquiry: A Tool for Presenting and Sharing Contextual Knowledge. In: Proceedings of the Nordic Design Research Conference: 'Making Design Matter', NORDES 2011, Helsinki (2011)

9. Sandberg, F.: Co-creating collaborative food service opportunities through work context maps. In: 3rd Nordic Conference on Service Design and Service Innovation, ServDes (2012)

10. Sanders: Convivial Toolbox: generative research for the front-end of design. BIS Publishers, Amsterdam (2012)

11. Star, S.L., Griesemer, J.R.: Institutional Ecology, 'Translations' and Boundary Objects: Amateurs and Professionals in Berkeley's Museum of Vertebrate Zoology. Social Studies of Science 19(3), 387-420 (1989)

12. Westerlund, B.: Design space exploration: co-operative creation of Proposals for Desired interactions with future artefacts. KTH, Stockholm (2009) 